\title{
NÚMERO 52
}

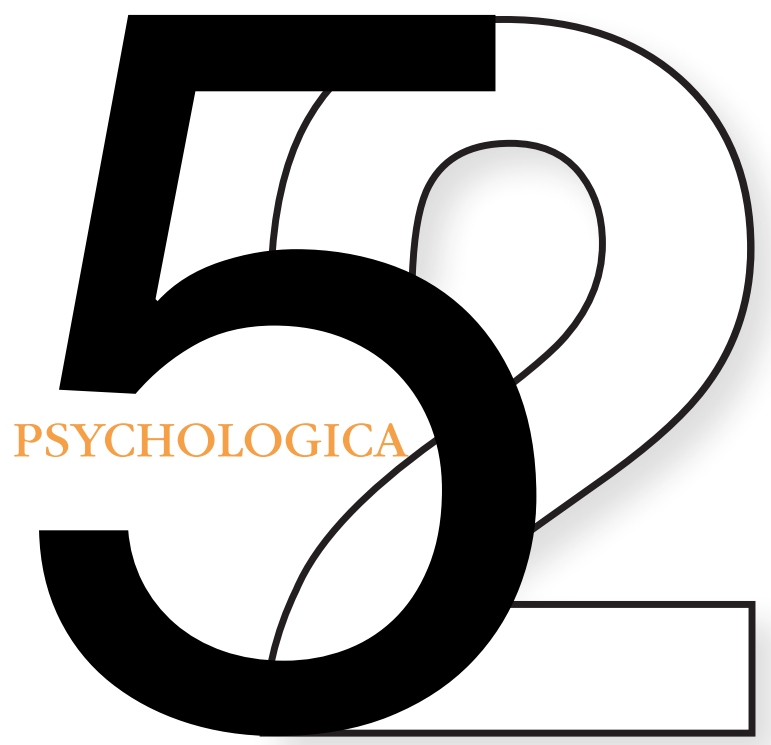

VOLUME I

IMPRENSA DA UNIVERSIDADE DE COIMBRA

FACULDADE DE PSICOLOGIA E DE CIÊNCIAS DA EDUCAÇÃO DA UNIVERSIDADE DE COIMBRA

\section{Versão integral disponível em digitalis.uc.pt}




\title{
Competência Percebida e Realização Escolar: Que Relações em Alunos do Ensino Secundário?
}

\author{
Joana Stocker, Sílvia Pina Neves e Luísa Faria'
}

Será que alunos com níveis elevados de competência percebida (competência emocional, concepções pessoais de inteligência, auto-eficácia, auto-conceito e dimensões causais) atingem melhores resultados escolares? Para o averiguar realizámos um estudo com 385 estudantes do secundário do Porto. Administraram-se o Questionário Compósito de Competência Percebida (Faria, Stocker \& Pina Neves, 2009), com 162 itens, e um Questionário Sócio-Demográfico, com 23 itens. Análises correlacionais indicam que auto-conceito e auto-eficácia são os construtos motivacionais que mais se relacionam com o rendimento, seguidos das dimensões causais, competência emocional e concepções pessoais de inteligência. Análises de regressão linear múltipla para o rendimento a Português, Matemática e global, apontam para o autoconceito, a auto-eficácia e as concepções pessoais de inteligência como principais preditores: percepções elevadas de competência e eficácia e concepções estáticas influenciam positivamente o aproveitamento, explicando os respectivos modelos, $44 \%, 53 \%$ e $47 \%$ da variância total, confirmando a importância da competência percebida no sucesso escolar.

PALAVRAS-CHAVE: Competência percebida, Motivação, Rendimento escolar, Ensino secundário.

\section{Introdução}

O sistema de ensino em geral, e o ensino secundário em particular, assistiram nas últimas décadas a um aumento exponencial do número de alunos matriculados, devido à generalização do acesso à escola (Gabinete de Estatística e Planeamento da Educação [GEPE], 2009). Assim, entre 1960 e 2007 o número de alunos matriculados no ensino secundário cresceu cerca de 27 vezes (de 13.116 para 349.477 alunos - GEPE,

1 Faculdade de Psicologia e de Ciências da Educação da Universidade do Porto (FPCEUP) - Ifaria@fpce.up.pt Esta investigação foi financiada pela Fundação para a Ciência e Tecnologia, pelo Ministério da Educação e pelo FEDER, no âmbito do Projecto "Concepções pessoais de competência de alunos e eficácia colectiva de turmas, professores e escolas: Contributos para a promoção do sucesso escolar no ensino secundário" (FSE/CED/83522/2008), e por duas bolsas da Fundação para a Ciência e Tecnologia, concedidas a Sílvia Pina Neves (SFRH/BPD/44530/2008) e a Joana Stocker (SFRH/BD/60225/2009). 
2009). Consequentemente, cumprindo os objectivos inicialmente propostos, a taxa de escolaridade deste ciclo de ensino aumentou de 1,3\% para 60\% (GEPE, 2009).

A par destas mudanças, e decorrendo das mesmas, a taxa de retenção e desistência no ensino secundário, apesar de ter diminuído desde o ano lectivo de $2000 / 2001$ (onde atingiu os $40 \%$ ), continua a ser elevada $-22 \%$ no ano lectivo de $2007 / 2008$ (GEPE, 2009). Analisando apenas o $12^{\circ}$ ano, verificamos que esta taxa de desistência/retenção foi de $35 \%$, sendo este o ano do secundário onde mais alunos ficam retidos ou abandonam a escola.

Outro indicador de insucesso escolar no ensino secundário é a diferença entre a taxa bruta de escolarização (número total de alunos matriculados, independentemente da idade) e a taxa real de escolarização (número total de alunos matriculados em idade normal de frequência deste ciclo de estudos) - 100\% vs. 60\% (GEPE, 2009) -, significando que $40 \%$ dos alunos terá mais de 18 anos.

Assim, o facto de o contexto de ensino secundário não estar, possivelmente, preparado para receber tão elevado número de alunos em tão reduzido período de tempo, provenientes de meios sócio-económicos diversos, com diferentes percursos escolares, expectativas, objectivos e motivações, pode ter dificultado uma resposta eficaz por parte da comunidade educativa (Formosinho \& Machado, 2008; Stocker \& Faria, 2009). A título de exemplo, temos que: (a) o elevado número de alunos por escola e turma tende a provocar o aumento dos conflitos e a diminuir o rendimento individual; (b) turmas demasiado heterogéneas dificultam a gestão da aula e a coesão do grupo; (c) a desarticulação dos programas leva à repetição de conteúdos de modo incoerente, ao longo dos anos e das disciplinas, conduzindo ao desinteresse dos alunos; (d) a elevada carga horária dificulta o envolvimento dos alunos em actividades extracurriculares e em hábitos de convivência; e (e) as estratégias de ensino e de motivação, por vezes inadequadas às características da turma/aluno, podem conduzir a uma relação pedagógica e a resultados escolares negativos (Formosinho \& Machado, 2008).

Ao mesmo tempo, sabemos que quanto mais elevado o grau académico, maiores são as exigências sobre os alunos e mais difícil se torna obter notoriedade. Ora, o ensino secundário constitui um ciclo de transição do ensino básico para o ensino superior ou para o mundo do trabalho, integrando, pois, desafios acrescidos que o aluno deve ultrapassar. Assim vejamos: (a) novas metodologias de ensino e de avaliação; (b) matérias mais exigentes; (c) contexto relacional professor-aluno menos próximo; (d) ambiente mais competitivo, susceptivel de criar maiores níveis de ansiedade e de stress; (e) tomada de decisões vocacionais; e (f) expectativas negativas de emprego ou de acesso ao ensino superior, pautadas quer pelas elevadas taxas de desemprego, quer pelos reduzidos numerus clausus (Azevedo \& Faria, 2006; Pina Neves \& Faria, 2007; Stocker \& Faria, 2009). 